\title{
Study on the Construction of the Legal Guarantee System of Ecological Civilization Construction at Present
}

\author{
Qian Li \\ Guizhou University of Finance and Economics, Guizhou, 550025, China \\ Keywords: Ecological civilization; law; security system \\ Abstract: At present, China is vigorously developing the construction of ecological \\ civilization. The construction of ecological civilization is a systematic project that requires \\ the integration and collaboration of many resources. In the process of ecological \\ civilization construction and development, the value and role of the legal security system \\ are constantly being highlighted. This paper starts from the basic connotation of ecological \\ civilization, and analyzes the basic role of the legal security system, while discussing \\ future development strategies.
}

\section{Introduction}

In the whole process of the development and construction of spiritual civilization, how to promote the coordinated and sustainable development of spiritual and cultural undertakings from the basic requirements of civilized construction is a key point in the current research in the field of humanities. In this era, the idea of ecological civilization has begun to be raised and gradually attracted widespread attention from society. At present, the basic connotation of ecological civilization and ecological civilization construction has not reached a comprehensive consensus in the academic field. Among them, the more representative views are mainly reflected in the following aspects[1].

\section{The basic connotation of ecological civilization}

Ecological civilization emphasizes the harmony of elements. In the process of ecological civilization construction, there are many elements involved. Whether it is at the macro level of the superstructure, or the underlying design, or the integration of the cultural structure at the specific micro level, it needs to be in a harmonious state. Only when the elements of ecological civilization are in a harmonious state, the value of ecological civilization in promoting the construction and development of material civilization will gradually become prominent. Whether it is based on political ecological balance or cultural ecological balance, in the process of the entire construction of ecological civilization, the harmony between various elements is the key to the realization of the entire ecological civilization.

The comprehensiveness of ecological civilization construction. The construction of ecological civilization puts forward relatively high requirements for the overall top-level design. Therefore, looking at the whole process of ecological civilization construction and development, an extremely 
important feature or requirement is to pay attention to the sustained and all-round development of ecological civilization construction. This kind of development puts more specific requirements on the system and the rules. Therefore, in the process of building ecological civilization in the future, how to improve from the institutional level, especially in terms of laws and regulations, has become the main content of the future legal level. From a certain perspective, the comprehensiveness of ecological civilization construction needs to consider many influencing factors such as environment, society, humanities and legal system. The comprehensive development between these factors is the proper meaning of the realization of its civilized ecological construction system[2].

\section{The role of the legal guarantee system for ecological civilization construction}

\subsection{Guidance and normative role}

In the mission and significance of the existence of the law, guiding and regulating the behavior of the group is a basic responsibility. The construction of ecological civilization requires a series of specific actions to implement and realize. In the process of this implementation, due to many levels of subjective or objective reasons, there will be different degrees of anomie. If these actions are not corrected in time, they will directly affect the harmony and stability of ecological civilization construction. Therefore, through the implementation of relevant ecological civilization construction laws and regulations, it will form a guiding and normative role objectively. The ultimate goal of this role is to promote the steady development of ecological civilization in the future. If we say that in the process of constructing the entire ecological civilization, there is a lack of proper legal level maintenance and guidance guarantees. In the future development, it will inevitably show some kind of system level deficiency[3]. The guiding role of ecological civilization is as follows.

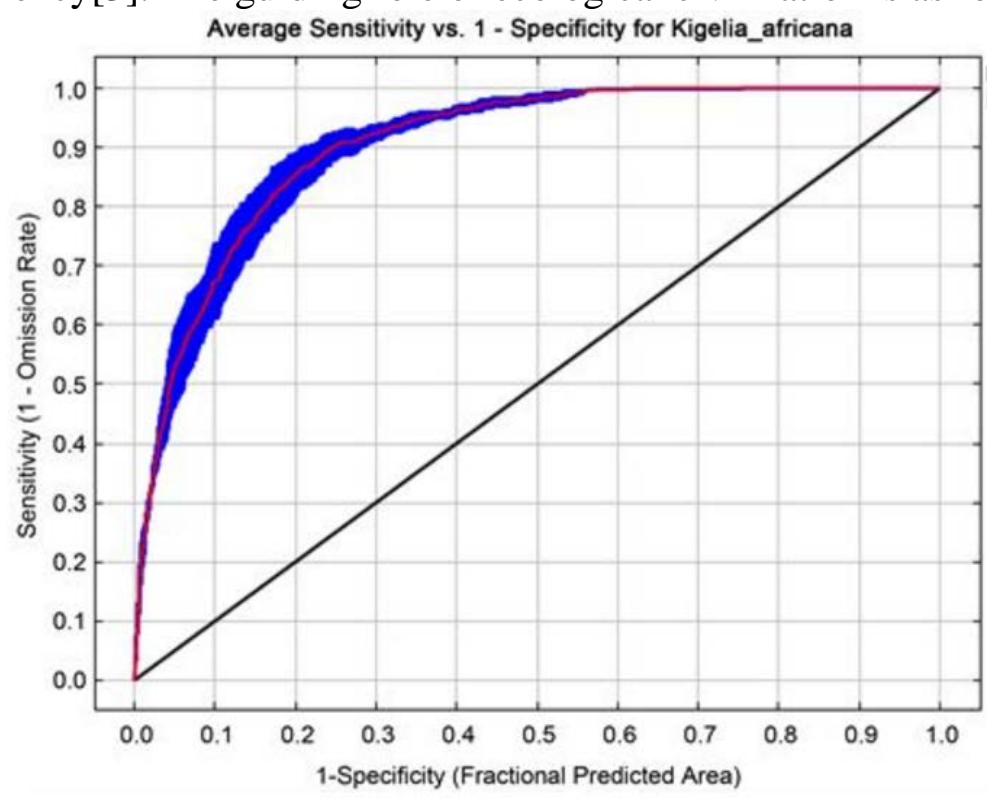

Fig.1 Guiding role of ecological civilization

\subsection{Play a catalytic role.}

In the process of the development of ecological civilization construction, the legal security system will act as a booster to provide more powerful policy support for the future construction of ecological civilization while conducting supervision and warning functions. Because the 
construction of ecological civilization is in the process of development, there will inevitably be certain differences, even conflicts at the level of interests. Such conflicts need to be reconciled and promoted with the help of the law. Without the coerciveness of such an external system, it will encounter some difficulties in development in the process of formulating and implementing rules in the future.

\section{The status quo of the construction of legal guarantee system for ecological civilization construction}

\subsection{The legal guarantee system for the construction of ecological civilization lacks the supervision of application}

In the process of building a socialist ecological civilization, especially in the process of building a legal security system, the necessary supervision is very important. However, from the perspective of overall development, China lacks corresponding system supervision in the construction of ecological civilization and legal security system. The lack or lack of such supervision at the level of the system is mainly reflected in the inadequacy of the formulation of relevant basic laws and regulations. Among them, the outstanding performance is that no specific lawsuits concerning the construction and development of ecological civilization have been made to carry out relevant laws and regulations. Timely revision. On the other hand, there is a certain degree of subjectivity in the implementation of specific laws and regulations. This problem not only affects the development process of ecological civilization construction, but also affects the authority and credibility of the law itself. This requires improvement and improvement in the future reform of the judicial system. The distribution of ecological funds is as follows.

$$
G(x, y)=\frac{1}{2 \pi \sigma^{2}} e^{-\frac{x^{2}+y^{2}}{2 \sigma^{2}}}
$$

\subsection{The supporting institutions for the construction of ecological civilization are not perfect}

In the process of building an ecological civilization, it requires the cooperation of many social resources to achieve more substantial development. However, in the process of China's ecological civilization construction and development, the lack of corresponding support institutions is a key to the impact of the legal guarantee system to play its basic role. The so-called support organization means that in the process of ecological civilization construction, a series of related institutions and resources, combined with their own development characteristics and advantages, contribute their own strength to the construction of ecological civilization, thus forming a good mutual aid with the legal security system. structure. Therefore, in the process of building and developing ecological civilization in the future, how to provide a greater level of guidance and support for the cooperation of relevant institutions in the construction of ecological civilization in the process of policy formulation and implementation requires continuous implementation. Discussion and research. Supporting the overall cooperation and cooperation of the institutions, the overall ecological civilization construction will avoid unnecessary resistance in the process of development, and thus achieve greater achievements in the process of building socialist ecological civilization[4]. 


\section{Strategies for improving the legal security system for ecological civilization construction}

\subsection{Do a good job in system management}

Today, in the comprehensive promotion of the legal system, the establishment and improvement of relevant systems from the source is one of the important solutions to reduce problems. It is clear that the scope of functions of the internal control of the legal supervision institution and the industry in which the authority engages, based on actual development and social horizontal industry standards, establish a system of self-improvement, and supervise the internal control regulations of the organization from both internal and external aspects. In the specific work, it is necessary to take the implementation of internal control norms as an opportunity to intensify the supervision and inspection of the basics of legal supervision, and introduce advanced scientific inspection methods to improve the internal control and management of legal supervision institutions.

\subsection{Do a good job of talent reserved}

In the future development process, we must fully rely on the strength of colleges and universities to do a good job in cultivating and storing legally relevant talents in ecological civilization construction. On the one hand, in terms of the direction of talent cultivation, we constantly seek to develop from the era of ecological civilization construction, and carry out continuous scientific planning and systematic improvement of the training norms of ecological civilization construction talents, especially the personnel training of the legal security system. On the other hand, in terms of the use of relevant talents, we must proceed from the basic concept of ecological civilization construction and provide the necessary foundation for the comprehensive development of talents and the realization of their own values. Only by taking the issue of talent as a key issue, the foundation of the legal guarantee system in the future construction of ecological civilization will be more solid and solid.

\section{Summary}

The construction of ecological civilization and the construction of legal guarantee system is a systematic project, which needs to be continuously enriched and improved in the future social practice. This paper briefly discusses the role of the construction of the legal guarantee system in the construction of ecological civilization, as well as the future improvement and improvement strategies, hoping to promote the deepening and improvement of relevant theoretical research.

\section{References}

[1] Sheng Wu Zhang,Pei Ji Shi,Hui Li. On the Water Ecological Civilization Construction and Strategic Measures of the Sustainable Utilization of Water Resources in Shiyang River Basin [J]. Applied Mechanics and Materials, 2014, 3547(675).

[2] Yu Hong He,Li Zhang. Automobile Consumption and Ecological Civilization Construction [J]. Advanced Materials Research, 2015, 3702(1073).

[3] Guo Zhu Huang,Tan Zhu,Jun Hu,Tie Wen,Yi Jun Ji. Exploring Ecological Land Reclamation to Promote the Ecological Civilization Construction in China [J]. Advanced Materials Research, 2015, 3702(1073).

[4] Jinwei QING. The Route Probing of New Rural Construction under the Perspective of Ecological Civilization [J]. Management Science and Engineering, 2014,8(4). 